\title{
Cold Flow Simulation for an IC Engine with Different Lengths of Connecting Rod
}

\author{
M. Zunaid ${ }^{1}$, Lavya Upadhyay ${ }^{2}$, NamanGupta ${ }^{3}$, Shubham Kushwaha ${ }^{4}$ \\ 1, 2, 3,4 (Department of Mechanical Engineering, Delhi Technological University, Bawana Road,Delhi, India)
}

\begin{abstract}
During the combustion period of an internal combustion engine,rotating flow or swirl can considerably increase the intensity of turbulence of the air-fuel mixture. This, in turn, can lead to increase in thermal efficiency. By varying the connecting rod length, swirl can be varied. Meaningful curves for swirl ratio are obtained by running cold flow simulations in ANSYS FLUENT for different connecting rod lengths and for different engine speeds (high and low). Dynamic air motion is visualized and velocity magnitude is plotted for thedifferent crank angle from $0^{\circ}$ to $720^{\circ}$ for the ANSYS IC Engine module. Finally, swirl ratios obtained for different lengths of connecting rods for an engine speed are compared.
\end{abstract}

Keywords: ANSYS FLUENT, Cold Flow Simulation, Connecting rod length, Swirl

\section{Introduction}

There is a huge need for developing eco-friendly and economically feasible automobiles and simultaneously meet the demands for high performance. This requires constant innovation and new engine conceptions in order to keep up with the growing demands of the $21^{\text {st }}$ century.The development of fuel-air mixture in the cylinder affects the performance, efficiency and emission formation of SI engines. To improve combustion, performance, and efficiency of the engine,the fluid flow dynamics play a vitalrole in the air-fuel mixture formation. The air motion inside the cylinder is affected mainly by manifold design, inlet and exhaust valve profile and combustion chamber setup. Due to high velocities involved, all flows into, out of and within cylinders are turbulent. Because of turbulence, there is a rise in combustion rates, increased heat transfer, evaporation and mixing. The turbulence throughout the combustion cycle considerably depends on the airflow (rotating) in the cylinder (Swirl and Tumble). Thus increase in turbulence (as a function of swirl) may lead to a decrease in the burning period and an increase in the thermal efficiency. Swirl (rotational motion about an axis parallel to the axis of the cylinder) and tumble (rotational motion about an axis perpendicular to the cylinder axis) escalate flame propagation speed, reduce cyclical variations, and expand the lean limit, though excessive rotational motion can have harmful effects on theflow resistance of the induction system and on heat transfer and efficiency. [1-3].

The aforementioned problems are difficult to solve by the experimental techniques due to the severe conditions inside an IC Engine (High Temperature and Pressure). Alternatively, computer simulations (Computational Fluid Dynamics, CFD) enable us to carry out iterative parameter studies with well-defined boundary conditions to test various configurations. Examination of common fluid flow patterns from CFD simulations, namely, swirl and tumble motion typical of automotive engines, and their variation with the length of connecting rod is done. The results of the analysis are used to inspect the homogeneousness of the air-fuel mixture structure for improved combustion process and enhanced engine performance. IC engine module of the ANSYS is used to carry out the simulations. Mean effective pressure is directly proportional to the swirl ratio induced, thus higher the swirl ratio better is the combustion [4-5].

The following are the objectives of the paper

1) To study the air motion inside the cylinder for different lengths of connecting rod at two different RPMs.

2) To compare the swirl ratio for the above air motion study.

\subsection{Cold Flow Analysis}

\section{Methodology}

In cold flow analysis,the engine is modeled without taking into consideration the chemical reactions occurring in the combustion stage. Only the airflow inside the engine is modeled and configured. The objective is to capture the air movement by studying the interface of constantly varying geometry with the dynamics of the fluid during the intake process. This enables us to determine the characteristics of airflow (swirl and tumble) in the cylinder as the intake and exhaust valve open and close at their specified time intervals.

High turbulence intensityaids rapid flame propagation. It also helps in better combustion during the power stroke. A homogeneous and high turbulent airflow is very critical to maintain correct fuel/air ratio. 


\subsection{Geometry}

Finite Element analysis was used to determine the characteristics of the IC Engine. The model was imported into Finite Element preprocessing tool ANSYS MESH for the meshing analysis. The model was then imported into Finite Element solver tool ANSYS FLUENT for post-processing the results.

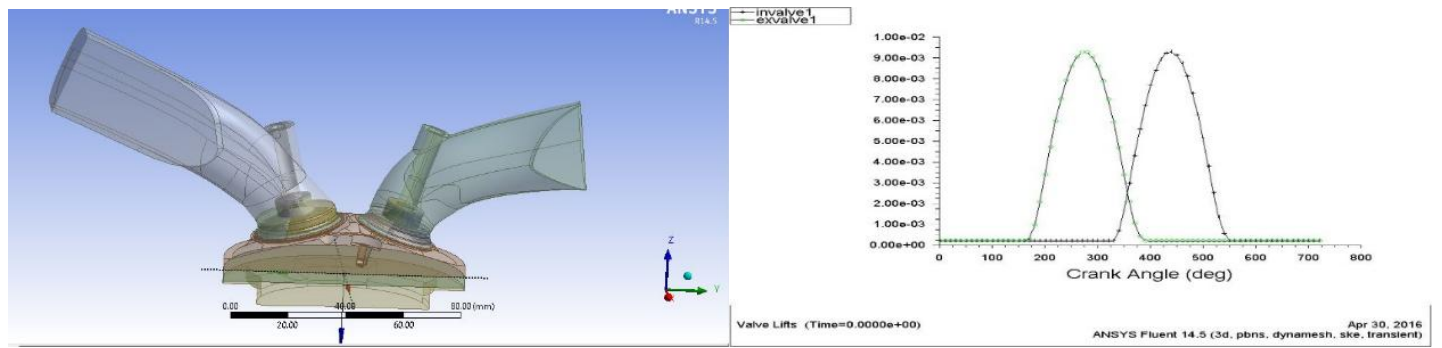

Fig 1.The geometry of the engineFig 2.Valve Lift Profile in the engine used

\subsection{Meshing}

Meshing is done using the decomposed geometry (Each part of the geometry is well defined). IC Engine meshing tool helps in minimizing the effort required to generate a mesh for the IC Engine solver. Nameselectionsare created in the decomposed file, which are used to identify different zones. This helps in creating essential mesh controlsDecomposition partitions a volume into further smaller volumes. These are then meshed individually. Dynamic meshing is used as the combustion chamber expands and compresses withachange in crank angle.

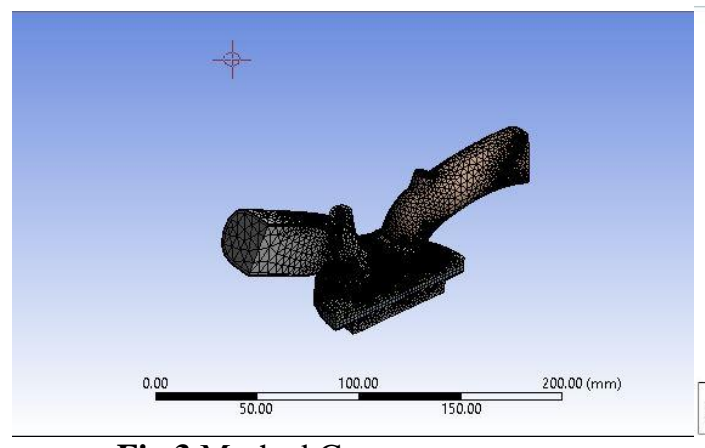

Fig 3.Meshed Geometry

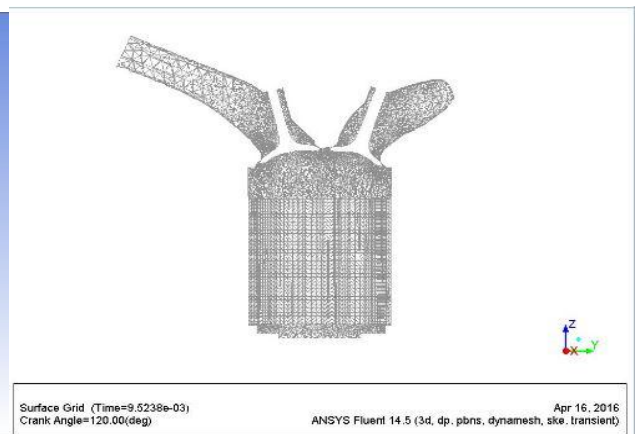

Fig 4. Dynamic Meshing

\subsection{Simulation}

Simulation is carried out using parameter valve lift. Dynamic motion is visualized and velocity magnitude is plotted for crank angle starting from $0^{\circ}$ to $720^{\circ}$. All the necessary inputs required to simulate the engine were input and the simulation was carried out. Result revealed the swirl and tumble regions of fluid and piston layer. Swirl, $\mathrm{X}$-axis tumble, $\mathrm{Y}$-axis tumble and moment of inertia were written in arunning directory in text file [6-7].

There is a small range of connecting rod to crank radius ratios, as the rod angle should not encourage excessive friction as it decreases the thermal efficiency. The optimum ratio lies between 1.4 and 2.2.The crank radius chosen for the given engine is $48 \mathrm{~mm}$. The simulation was carried out for four different connecting rod lengths over twoengine speeds- low speed $(2100 \mathrm{rpm})$ and high speed $(5000 \mathrm{rpm})$. The connecting rod lengths taken were $150 \mathrm{~mm}, 170 \mathrm{~mm}, 180 \mathrm{~mm}$, and $200 \mathrm{~mm}$. Four cases of connecting rod lengths were evaluated over each engine speed keeping the crank radius constant [8].

The engine specifications used are given below in the table.

Table 1.Specifications of the engine used

\begin{tabular}{|l|l|l|}
\hline S.No. & Parts & Dimensions \\
\hline 1. & Connecting Rod Lengths & a] $150 \mathrm{~mm}$ \\
& & b] $170 \mathrm{~mm}$ \\
& & c] $180 \mathrm{~mm}$ \\
& & d] $200 \mathrm{~mm}$ \\
\hline 2. & Engine Speed & a] $2100 \mathrm{rpm}$ (low speed) \\
& & b] $5000 \mathrm{rpm}$ (high speed) \\
\hline 3. & Crank radius & $48 \mathrm{~mm}$ \\
\hline 4. & Valve lift & $0.2 \quad \mathrm{Mm}$ \\
\hline
\end{tabular}


a. Simulation of every time step consisted of $1^{\circ}$ crank angle and thus 720 time steps were set for thecalculation to simulate one complete cycle of IC engine.

b. Swirl ratios were plotted by visualizing dynamic motion stating from crank angle $0^{\circ}$ to $720^{\circ}$

c. The simulation results are plotted as agraph between swirl ratio and crank angle.

\section{Results And Discussions}

Fig 5 shows the variation of exhaust velocities for connecting rod lengths of $150 \mathrm{~mm}, 170 \mathrm{~mm}, 180 \mathrm{~mm}$ \& $200 \mathrm{~mm}$ at $2100 \mathrm{rpm}$ and $5000 \mathrm{rpm}$. Fig 5.a shows maximum exhaust velocity for a given connecting rod length at $2100 \mathrm{rpm}$. Maximum exhaust velocity decreases as the connecting rod length is increased. The values of maximum exhaust velocity for a given connecting rod length at $2100 \mathrm{rpm}$ have been tabulated in Table 2.Fig 5.bshows maximum exhaust velocity for a given connecting rod length at $5000 \mathrm{rpm}$. The maximum exhaust velocity does not vary much for a given connecting rod length as in the above case. The values of maximum exhaust velocity for a given connecting rod length at $5000 \mathrm{rpm}$ have been tabulated in Table 3 .

Table 2. Comparison of Exhaust velocities at $2100 \mathrm{rpm}$

\begin{tabular}{|l|l|l|}
\hline $\begin{array}{l}\text { Connecting } \\
\text { Rod Length } \\
(\mathbf{m m})\end{array}$ & $\begin{array}{l}\text { Crank Angle } \\
\text { (degrees) }\end{array}$ & $\begin{array}{l}\text { Maximum } \\
\text { Exhaust } \\
\text { Velocity } \\
(\mathbf{m} / \mathbf{s})\end{array}$ \\
\hline 150 & 268 & 180 \\
\hline 170 & 268 & 165 \\
\hline 180 & 296.50 & 150 \\
\hline 200 & 300 & 128 \\
\hline
\end{tabular}

Table 3. Comparison of Exhaust velocities at $5000 \mathrm{rpm}$

\begin{tabular}{|l|l|l|}
\hline $\begin{array}{l}\text { Connecting } \\
\text { Rod Length } \\
(\mathbf{m m})\end{array}$ & $\begin{array}{l}\text { Crank } \\
\text { Angle } \\
\text { (degrees) }\end{array}$ & $\begin{array}{l}\text { Maximum } \\
\text { Exhaust } \\
\text { Velocity } \\
(\mathbf{m} / \mathbf{s})\end{array}$ \\
\hline 150 & 320 & 375 \\
\hline 170 & 320 & 373 \\
\hline 180 & 320 & 375 \\
\hline 200 & 320 & 371 \\
\hline
\end{tabular}

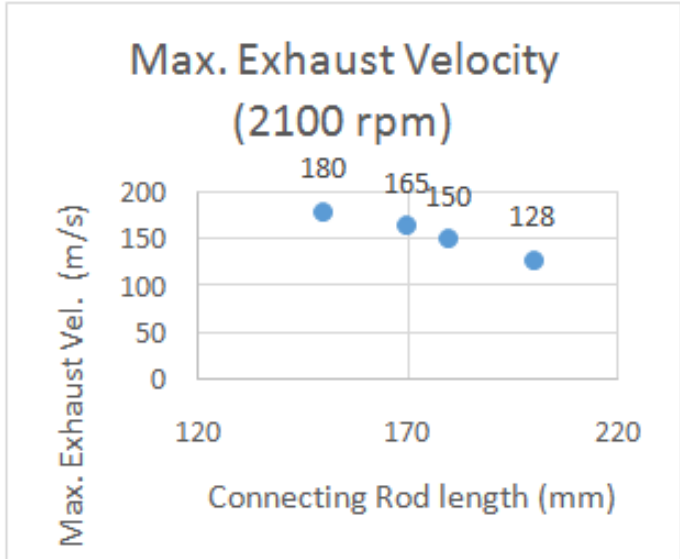

Fig 5.a

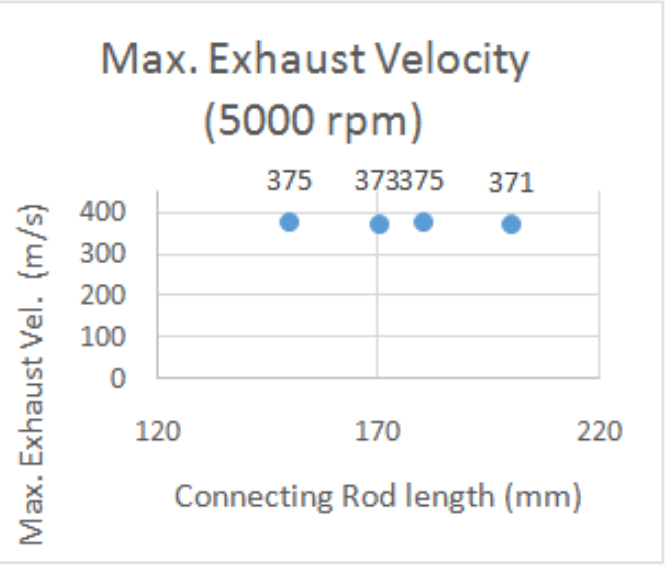

Fig 5.b

Fig 5 Variation of Exhaust Velocitiesfor connecting rod lengths of 150mm, 170mm, 180mm \& 200mm at a) $2100 \mathrm{rpm}$ b) $5000 \mathrm{rpm}$

Fig 6gives a comparison between the different swirl ratios obtained for connecting rod lengths of $150 \mathrm{~mm}, 170 \mathrm{~mm}, 180 \mathrm{~mm} \& 200 \mathrm{~mm}$ at $2100 \mathrm{rpm}$ and $5000 \mathrm{rpm}$. Fig6.ashows considerable variation in swirl ratio for change in the length of connecting rod length from $150 \mathrm{~mm}$ to $200 \mathrm{~mm}$ at $2100 \mathrm{rpm}$. Fig 6.b shows no such degree of variation in swirl ratio for change in connecting rod length from $150 \mathrm{~mm}$ to $200 \mathrm{~mm}$ at $5000 \mathrm{rpm}$ as in the above case. 


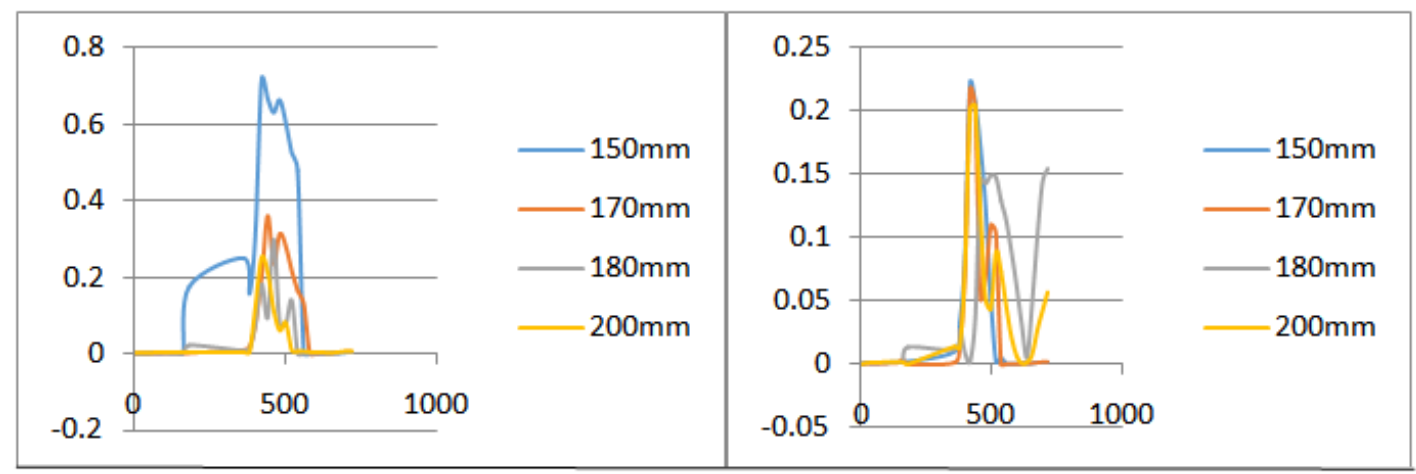

Fig 6.a

Fig 6.b

Fig 6 Comparison between different swirl ratios at a) $2100 \mathrm{rpm}$ b) $5000 \mathrm{rpm}$

Fig 7shows the velocity contoursfor connecting rod lengths of $150 \mathrm{~mm}, 170 \mathrm{~mm}, 180 \mathrm{~mm} \& 200 \mathrm{~mm}$ when the exhaust velocity is maximum at $2100 \mathrm{rpm}$ and at corresponding crank angles. InFig 7.a for $150 \mathrm{~mm}$ connecting rod length, the maximum exhaust velocity obtained is $180 \mathrm{~m} / \mathrm{s}$ at acrank angle of $268^{\circ}$. InFig 7.b, for $170 \mathrm{~mm}$ connecting rod length, the maximum exhaust velocity obtained is $165 \mathrm{~m} / \mathrm{s}$ at acrank angle of $268^{\circ}$. InFig 7.cfor $180 \mathrm{~mm}$ connecting rod length, the maximum exhaust velocity obtained is $150 \mathrm{~m} / \mathrm{s}$ at acrank angle of $296.5^{\circ}$.InFig 7.d,For $200 \mathrm{~mm}$ connecting rod length, the maximum exhaust velocity obtained is $128 \mathrm{~m} / \mathrm{s}$ at crank angle of $300^{\circ}$.

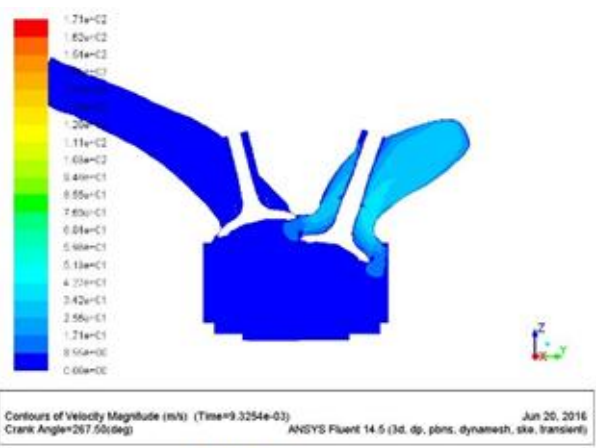

Fig 7.a

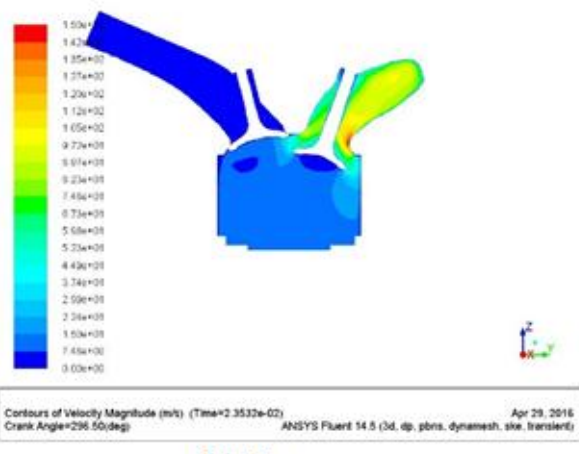

Fig 7.c

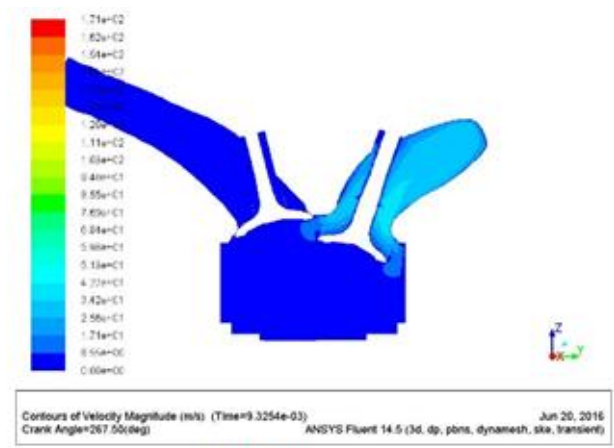

Fig 7.b

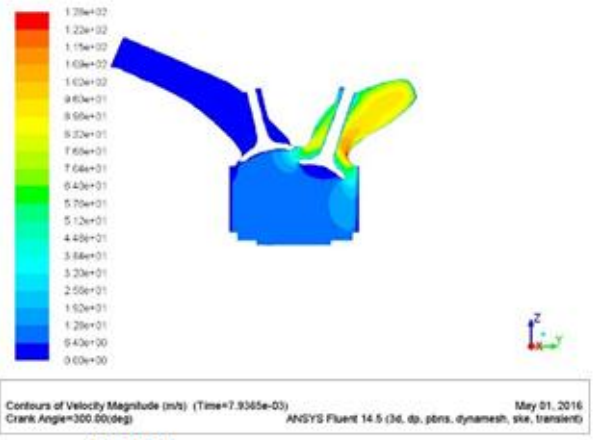

Fig7.d

Fig 7Velocity contours for different connecting rod lengths when the exhaust velocity is maximum at $2100 \mathrm{rpm}$ and at corresponding crank angle

Fig 8shows the velocity contour for connecting rod lengths of $150 \mathrm{~mm}, 170 \mathrm{~mm}, 180 \mathrm{~mm} \& 200 \mathrm{~mm}$ when the exhaust velocity is maximum at $5000 \mathrm{rpm}$ and at corresponding crank angles. In Fig 8.a, for $150 \mathrm{~mm}$ connecting rod length, the maximum exhaust velocity obtained is $375 \mathrm{~m} / \mathrm{s}$ at acrank angle of $320^{\circ}$. InFig 8.b,For $170 \mathrm{~mm}$ connecting rod length, the maximum exhaust velocity obtained is $373 \mathrm{~m} / \mathrm{s}$ at acrank angle of $320^{\circ}$. InFig 8.c for $180 \mathrm{~mm}$ connecting rod length, the maximum exhaust velocity obtained is $375 \mathrm{~m} / \mathrm{s}$ at acrank angle of $320^{\circ}$. In Fig 8.d,For $200 \mathrm{~mm}$ connecting rod length, the maximum exhaust velocity obtained is $371 \mathrm{~m} / \mathrm{s}$ at acrank angle of $320^{\circ}$. 


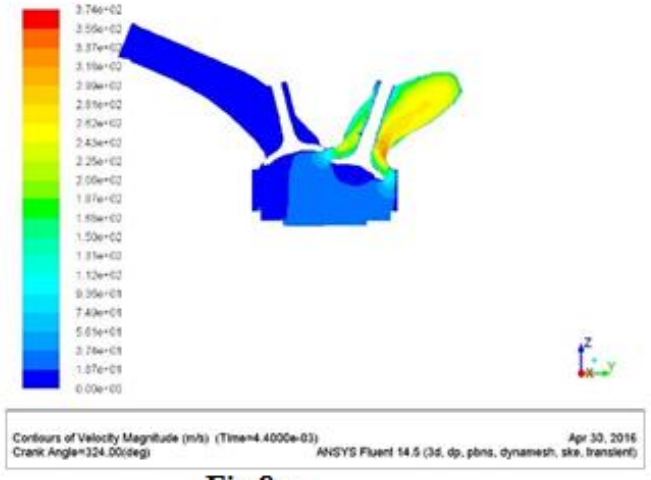

Fig 8.a

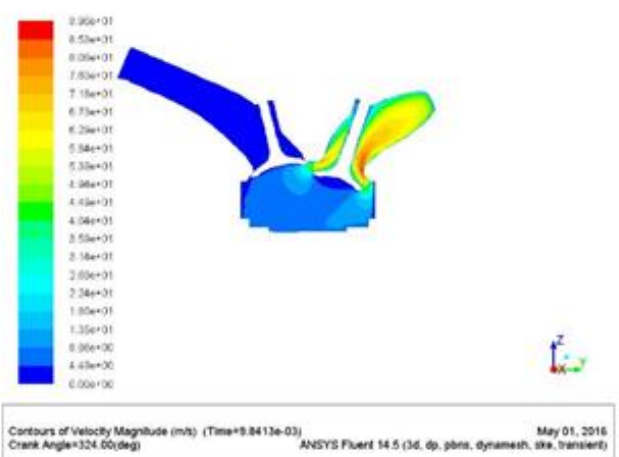

Fig 8.b

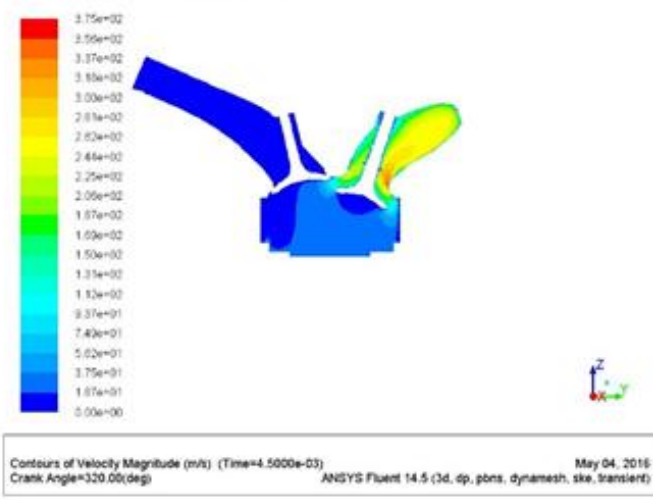

Fig 8.c

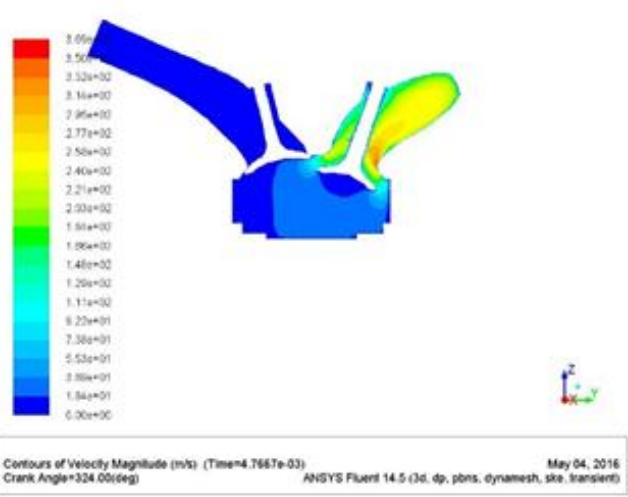

Fig 8.d

Fig 8 Velocity contours for different connecting rod lengths when the exhaust velocity is maximum at $5000 \mathrm{rpm}$ and at corresponding crank angles

\section{Conclusion}

The variation of the swirl ratio a for different lengths of connecting rod has been studied at 2100rpm and 5000rpm of the engine. The smallest connecting rod of length $150 \mathrm{~mm}$ gives maximum swirl ratio in the intake stroke when compared to the maximum swirl ratio in the intake stroke given by engines with longer connecting rods of length $170 \mathrm{~mm}, 180 \mathrm{~mm}$ and $200 \mathrm{~mm}$ for $2100 \mathrm{rpm}$. Hence, for an engine to achieve the maximum intake swirl ratio at low rpms, the connecting rod length can be varied without affecting the swirl behaviour at higher rpms. The shorter the length of the connecting rod the higher the value of maximum swirl ratio in the intake stroke can be achieved. This would amount to better combustion of the fuel without any residues left in the exhaust and thus increase power and efficiency of the engine.

\section{References}

[1] Nagayama, I., Araki, Y., and Iioka, Y., "Effects of Swirl and Squish on S.I. Engine Combustion and Emission," SAE Technical Paper 770217, 1977, doi: 10.4271/770217.

[2] Karthikeyan CP, LakshmanA and Davidson Jebaseelan, "CFD studies on In-cylinder air motion during different strokes of an IC Engine", SET Conference, VIT University Chennai, (2012).

[3] Rohith.S, Dr. G.V. Naveen Prakash." Cold Flow Simulation in an IC Engine "International Research Journal of Engineering and Technology, Volume-2, Issue 7,e-ISSN:2395-0056 p-ISSN:2395-0072

[4] S K Gugulothu,K H C Reddy, "CFD Simulation of In-Cylinder Flow on Different Piston Bowl Geometries in a DI Diesel Engine" Journal of Applied Fluid Mechanics,Volume 9 Issue No.3, ISSN:1735-3572,EISSN:1735-3645

[5] R. ThundilKaruppa Raj and R. Manimaran"Effect of Swirl in a Constant Speed DI Diesel Engine using Computational Fluid Dynamics"ISSRES volume -4, Issue- 4.

[6] PathakYogesh R, Deore Kailas D and PatilVijayendra M "In-cylinder cold flow CFD simulation of IC Engine using Hybrid Approach" 2321-7308.

[7] Victor IORGA-SIMAN,AdrianCLENCI,PierrePODEVIN,Alain DELACROIX and Ion TABACU "In-Cylinder Flow Analysis of Different Valve Lift Using CFD" University of Pitesti, Scientific Bulletin, Automotive Series, vol. 21 (2).

[8] Suzuki, M., Iijima, S., Maehara, H., and Moriyoshi, Y., "Effect of the Ratio between Connecting-rod Length and Crank Radius on Thermal Efficiency," SAE Technical Paper 2006-32-0098, 2006, doi: 10.4271/2006-32-0098. 